\title{
VULNERABILIDADE SOCIAL E EXCLUSÃO DIGITAL EM TEMPOS DE PANDEMIA: UMA ANÁLISE DA DESIGUALDADE DE ACESSO À INTERNET NA PERIFERIA DE CURITIBA
}

\author{
Marcelo Nogueira de Souza ${ }^{\mathrm{i}}$ \\ Lislaine Mara da Silva Guimarães ${ }^{\text {ii }}$
}

\begin{abstract}
Resumo: O objetivo do presente artigo é contribuir para o mapeamento das diferentes situações indicativas de exclusão e vulnerabilidade social na cidade de Curitiba, com base numa análise comparativa sobre como se dá o acesso à Internet em bairros da região central e da periferia da cidade. Como se procura demonstrar, a suspensão das aulas presenciais, em razão da pandemia de Covid-19 e a adoção da educação a distância - que não contempla o alunado que vive em condição de vulnerabilidade social, em decorrência de fatores socioeconômicos e que, consequentemente, não possui acesso aos recursos tecnológicos necessários - tem revelado outro aspecto da seletividade social das medidas adotadas pelo município no enfrentamento da pandemia.
\end{abstract}

Palavras-chave: Desigualdade social; Inclusão digital; Periferias; Covid-19.

\section{SOCIAL VULNERABILITY AND DIGITAL EXCLUSION IN PANDEMIC TIMES: AN ANALYSIS OF THE INEQUALITY OF INTERNET ACCESS IN THE PERIPHERY OF CURITIBA}

\begin{abstract}
The purpose of this article is to contribute to the mapping of the different situations indicating exclusion and social vulnerability in the city of Curitiba, based on a comparative analysis of how Internet access occurs in neighborhoods in the central region and on the outskirts of the city. As we try to demonstrate, the suspension of face-to-face classes, due to the Covid-19 pandemic and the adoption of distance education - which does not include students who live in conditions of social vulnerability, due to socioeconomic factors and, consequently, not has access to the necessary technological resources - it has revealed another aspect of the social selectivity of the measures adopted by the municipality to face the pandemic.
\end{abstract}

Keywords: Social inequality; Digital inclusion; Peripheries; Covid-19.

\section{Introdução}

A análise da literatura a respeito de estudos realizados no campo da sociologia urbana revela que tem crescido o número de pesquisas que associam a organização social do território às inúmeras formas de desigualdade. Tais estudos, em geral, têm utilizado os termos "efeito vizinhança", "efeito-território" ou, ainda, "efeito-bairro" para descrever modelos explicativos baseados na relação de causalidade entre determinados acontecimentos e o 
contexto social no qual ocorrem e adquirem especial relevância diante da atual pandemia de Covid-19.

Mesmo antes da pandemia, a imensa desigualdade no acesso à internet já era objeto de estudo de inúmeras pesquisas, como a TIC Domicílios, divulgada em 2019, e que já apontava que, apesar de $70 \%$ dos lares brasileiros, localizados em áreas urbanas, terem acesso à internet, o mesmo apresentava grandes disparidades. A análise por classe social, por exemplo, revelou que, entre os mais ricos (classes A e B), 96,5\% das casas têm sinal de internet; ao passo que nos patamares mais baixos da pirâmide (classes D e E), esse índice cai para 59\%. Além disso, entre a população cuja renda familiar é inferior a 1 salário mínimo, 78\% das pessoas com acesso à internet usam exclusivamente o celular.

Essa imensa desigualdade no acesso à internet adquire novos contornos diante da pandemia de Covid-19 pois, em razão do isolamento social recomendado pelas autoridades sanitárias, os sistemas de ensino passaram a adotar a educação a distância, que, da forma como foi implantada, tem se revelado como mais um indicativo da desigualdade social que sempre caracterizou a educação brasileira.

Considerando que o processo de segregação residencial desencadeia mecanismos que restringem o acesso de grupos sociais (em geral, moradores da região periférica) ao conjunto de oportunidades providas pelo Estado, o objetivo do presente artigo é contribuir para o mapeamento das diferentes situações indicativas de exclusão e vulnerabilidade social na cidade de Curitiba, com base numa análise comparativa sobre como se dá o acesso à internet em bairros da região central e da periferia da cidade.

Na primeira seção - O retrato da segregação e da desigualdade na "cidade modelo" através de uma revisão bibliográfica das obras de alguns dos principais pesquisadores da sociologia urbana, buscamos compreender os impactos da segregação espacial na região de Curitiba, que é marcada pela forma mais tradicional de segregação espacial, a oposição centro $\mathrm{x}$ periferia, onde os mais abastados situam-se próximos ao centro e os desfavorecidos economicamente habitam as periferias das cidades, distantes dos equipamentos e da infraestrutura.

$\mathrm{Na}$ segunda seção, intitulada "A desigualdade no acesso à internet em bairros da região central e periférica de Curitiba", apresentamos as análises empíricas do trabalho, procurando demonstrar como a educação a distância - por não contemplar aqueles que vivem em condição de vulnerabilidade social, em decorrência de fatores socioeconômicos e, consequentemente, não possuem acesso aos recursos tecnológicos necessários - tem revelado 
outro aspecto da seletividade social das medidas adotadas pelo Estado no enfrentamento da pandemia.

E, por fim, na última seção, apresentamos nossas considerações finais.

\section{O retrato da segregação e da desigualdade na "cidade modelo"}

A pandemia de Covid-19 - doença respiratória aguda causada pelo coronavírus da síndrome respiratória aguda grave 2 (SARS-CoV-2) - foi identificada pela primeira vez em Wuhan, na província de Hubei, República Popular da China, em 1 de dezembro de 2019. Desde então, tem feito milhões de vítimas fatais em todo o planeta, sendo o Brasil, atualmente, - assim como outros países da América Latina e E.U.A - o novo epicentro da doença.

Visando minimizar os impactos, autoridades sanitárias de todo o mundo passaram a recomendar medidas de distanciamento social, consideradas essenciais para o controle da doença. Ficar em casa passou a ser, desde então, palavra de ordem no enfrentamento da moléstia. No entanto, diante da atual conjuntura, o simples ato de ficar em casa adquire significados absolutamente diferentes, como bem ilustrado por Pretto, Bonilla e Sena (2020):

\footnotetext{
Em um país com uma enorme desigualdade social, como o Brasil, é necessário especificar que essa casa, para as classes média e alta, se constitui numa edificação com diversos cômodos, que permite arranjos para o desenvolvimento de atividades individuais e coletivas; já para as classes populares, a casa é, muitas vezes, um único cômodo, onde convivem muitas pessoas, de pequenos a idosos, o que torna praticamente impossível permanecer nesse espaço o dia todo, ou desenvolver qualquer tipo de atividade que exija o mínimo de concentração e dedicação, como são geralmente aquelas ligadas à experiência educacional. No entanto, com esse enorme contingente juvenil sem aula nas escolas, começam a surgir, aqui e em diversos países, soluções para que a educação continue, em casa, sob a responsabilidade dos grupos familiares. Portanto, as hashtags \#fiqueemcasa e \#aescolacontinua têm significados absolutamente diferentes para uma ou outra realidade, uma ou outra classe social (PRETTO, BONILLA, SENA, 2020, p. 2-3).
}

Assim, a pandemia tem escancarado a brutal desigualdade de oportunidades que sempre caracterizou o sistema educacional brasileiro. Desigualdade que se apresenta de diferentes formas, através do acesso a internet, por exemplo.

De acordo com dados do Mapa da Inclusão Digital (2018), Curitiba aparecia em quinto lugar no ranking de acesso a computador e internet, como demonstrado na tabela 1. 
Tabela 1: Ranking do Acesso por municípios - Computador e internet no município

\begin{tabular}{|c|c|c|c|c|c|c|c|}
\hline UF & \multicolumn{2}{|c|}{ Posição } & \multirow{2}{*}{$\begin{array}{r}\text { Computador } \\
77.62\end{array}$} & \multirow{2}{*}{$\begin{array}{l}\mathbf{U F} \\
S P\end{array}$} & \multicolumn{2}{|c|}{ Posição } & \multirow{2}{*}{$\begin{array}{r}\text { Computador } \\
\text { Com Internet } \\
74.07\end{array}$} \\
\hline$S P$ & $l$ & São Caetano do Sul & & & 1 & São Caetano do Sul & \\
\hline$S C$ & 2 & Florianópolis & 75.47 & ES & 2 & Vitória & 68.41 \\
\hline ES & 3 & Vitória & 73.88 & $S P$ & 3 & Santos & 67.83 \\
\hline$S P$ & 4 & Santos & 72.38 & $S C$ & 4 & Florianópolis & 67.67 \\
\hline$P R$ & 5 & Curitiba & 71.64 & $R J$ & 5 & Niterói & 62.72 \\
\hline$S P$ & 6 & Valinhos & 70.86 & $P R$ & 6 & Curitiba & 62.71 \\
\hline$S C$ & 7 & São José & 70.49 & $S P$ & 7 & Santo André & 61.40 \\
\hline$S C$ & 8 & Balneário Camboriú & 70.10 & $S C$ & 8 & São José & 60.57 \\
\hline$R J$ & 9 & Niterói & 69.20 & $S P$ & 9 & Valinhos & 60.24 \\
\hline$P R$ & 10 & Maringá & 69.18 & $S P$ & 10 & Americana & 60.05 \\
\hline
\end{tabular}

Fonte: Mapa da Inclusão Digital. CPS/FGV: Processando os microdados do Censo/IBGE (adaptado pelos autores).

Nos últimos anos presenciamos um crescimento do número de usuários de internet no Brasil. Contudo, essa expansão não é uniforme, apresentando desigualdades regionais no acesso e no uso, especialmente entre as áreas urbanas e rurais e de acordo com as diferentes classes sociais. Além disso, o acesso à internet também é ilustrativo da desigualdade intramunicipal que caracteriza as grandes cidades brasileiras.

No caso de Curitiba esta desigualdade se manifesta através da segregação espacial, caracterizada pela oposição centro x periferia, onde os mais abastados situam-se próximos ao centro e os desfavorecidos economicamente habitam as franjas das cidades, distantes dos equipamentos e infraestrutura e, também, como procuramos demonstrar na próxima seção, apresentam uma percentagem menor de domicílios com acesso à internet.

Curitiba é conhecida mundialmente como "a cidade modelo". De fato, em 2012, de acordo com o IBGE, Curitiba ocupava a $10^{\mathrm{a}}$ posição entre os 5.565 municípios brasileiros segundo o Índice de Desenvolvimento Humano Municipal (IDHM ${ }^{\mathrm{iii}}$ ), que abarca três dimensões: longevidade, educação e renda. Entretanto, dois anos antes, em 2010, era divulgado o relatório do Fórum Urbano Mundial da ONU e Curitiba figurava entre as mais desiguais do mundo, aparecendo em $17^{\circ}$ lugar no ranking global, sendo a quinta cidade mais desigual da América Latina. Ou seja, Curitiba é também reconhecida internacionalmente pela desigualdade social. 
O contraste da "cidade modelo" que é uma das mais desiguais do mundo tem suas raízes no planejamento urbano excludente, e pode ser entendido através da análise do Plano Diretor posto em prática, principalmente através das políticas habitacionais, na década de 1970. De acordo com Albuquerque (2007):

[...] o elemento mais explícito da política habitacional de Curitiba foi a periferização da população de baixa renda “(...) a produção habitacional da 'cidade modelo' empurrou os pobres de Curitiba para as bordas do Município" (ALBUQUERQUE, 2007, p.113).

Ainda, de acordo com Lojkine (1997), a forma mais tradicional da segregação espacial é a oposição centro x periferia, onde os mais abastados situam-se próximos ao centro e os desfavorecidos economicamente habitam as franjas das cidades, distantes dos equipamentos e infra-estrutura. Curitiba segue este padrão. Os bairros periféricos aqui analisados situam-se no extremo sul do município, bastante afastados dos bairros da região central.

De acordo com Carvalho e Sugai (2013), as ações e repercussões do Plano Diretor da cidade de Curitiba - elaborado durante a década de 1970 - assim como toda a dinâmica da "transformação" do espaço e da imagem da cidade revelaram-se contrários à produção de uma cidade mais democrática e igualitária. Ainda de acordo com os autores:

Observa-se, sobretudo, um claro interesse em afastar e invisibilizar pobreza e conflitos das partes da cidade que deveriam ser positivadas, midiatizadas e vendidas como um projeto bem sucedido de cidade viável, criativa, com boa qualidade de vida e oposta às demais caóticas e desorganizadas metrópoles brasileiras (CARVALHO, SUGAI, 2013, p.4-5).

O referido Plano Diretor da cidade de Curitiba, que remodelaria a estrutura urbana da cidade nas décadas seguintes, foi promulgado em 1971, justamente no momento em que cresciam no país os estudos que viriam a ser conhecidos como uma teoria da urbanização na periferia do capitalismo.

Teoria esta que foi fortemente influenciada pelo estruturalismo francês e seus teóricos, em especial Manuel Castells, que interpretaram a questão urbana, a partir de pesquisas desenvolvidas principalmente pelo Cebrap (Centro Brasileiro de Análise e Planejamento) e pela FAU-USP (Faculdade de Arquitetura e Urbanismo da Universidade de São Paulo).

Estes autores, procuraram analisar os efeitos do subdesenvolvimento na reprodução da força de trabalho - que se dá no espaço - a qual se dava de maneira bem diferente da que ocorria nos Estados de bem-estar social, gerando, consequentemente, uma urbanização também diferenciada. 
O próprio termo "periferia" deve a estes pesquisadores a sua ampliação conceitual, uma vez que, de acordo com Arantes (2009), as definições de "periferia" - assim como as de "espoliação urbana" e "autoconstrução" da moradia - serão fundamentais para aclimatar os conceitos da sociologia francesa ao nosso contexto.

Assim, aos poucos, a cidade passa de mero suporte de processos sociais e econômicos para ser compreendida - através de uma teoria crítica do urbano - como parte importante da produção e reprodução do capital. De acordo com Arantes (2009):

Assim, será retomada e reavaliada a teoria da "renda da terra", em suas articulações com o Estado e o "capital da construção", e formulada a hipótese de um "padrão periférico de crescimento da metrópole" (ARANTES, 2009, p. 104).

Segundo o autor, a conexão entre os referidos pesquisadores, formuladores de hipóteses para a interpretação da urbanização latino-americana, foi feita pelo sociólogo espanhol Manuel Castells - professor da Universidade de Paris e coordenador do Centro Interdisciplinar de Desenvolvimento Urbano e Regional de Santiago do Chile - que também foi o responsável pela organização do livro "Imperialismo e urbanização na América Latina".

O livro viria a se tornar um marco para a nascente crítica marxista sobre a questão urbana; tendo como participantes quatro pesquisadores do Cebrap - Paul Singer, Fernando Henrique Cardoso, Lúcio Kowarick, Cândido Ferreira de Camargo -, além do geógrafo Milton Santos.

Entre os pesquisadores da FAU-SP, vale a pena destacar as contribuições de Ermínia Maricato, que é a organizadora do livro "A produção da casa (e da cidade) no Brasil industrial" (1979), produção com textos de 1975 a 1979, que representou um importante avanço em relação à produção do Cebrap, principalmente por ter melhor desenvolvido e aprofundado os conceitos de "periferia", "espoliação" e "autoconstrução".

Além dela, Gabriel Bolaffi, sociólogo e professor da FAU, através de sua pesquisa sobre o Plano Nacional de Habitação - "Habitação e urbanismo: o problema e o falso problema" - supera o conceito de periferia como lugar físico e como pólo dual para caracterizar um movimento próprio do crescimento das cidades brasileiras, tomando São Paulo como seu exemplo mais predatório.

De acordo com Bolaffi, as ações do BNH não devem ser entendidas como desvio de rota, mas como regra da própria dinâmica urbana, que ele passa a denominar "padrão periférico de crescimento da metrópole". 
As principais críticas às análises de Castells - que irão influenciar a produção marxista sobre a questão urbana nos anos seguintes - se referiam ao fato destas delimitarem a cidade como espaço exclusivo de consumo coletivo de serviços do Estado, deixando de lado questões consideradas vitais na sociedade como o consumo e a cultura de massas.

Entre as produções do CEBRAP deste período vale a pena destacar o livro do economista Paul Singer, "Economia política da urbanização" (1973) e "Crítica à razão dualista" (1972) do economista e sociólogo Francisco de Oliveira.

Frente aos objetivos do presente trabalho, as pesquisas do grupo que desenvolvia a pesquisa sobre cidade, cultura de massas e movimentos populares urbanos, coordenado pelos sociólogos Lúcio Kowarick, Vinicius Caldeira Brant e Cândido Procópio de Camargo, adquirem especial relevância pelo destaque dado a questão da periferização das metrópoles em especial no livro "São Paulo 1975: crescimento e pobreza" (1976) - ainda que de forma descritiva e não analítica.

A parte analítica adquire relevo, principalmente, a partir do lançamento do livro de Lucio Kowarick, “A espoliação urbana” (1979), ou seja, a expulsão dos pobres para as periferias, característica do processo de urbanização no Brasil e decorrente da combinação de crescimento e pauperização.

A título de exemplo, a figura 1, abaixo, apresenta o mapa da cidade de Curitiba com cada uma de suas dez regionais. 


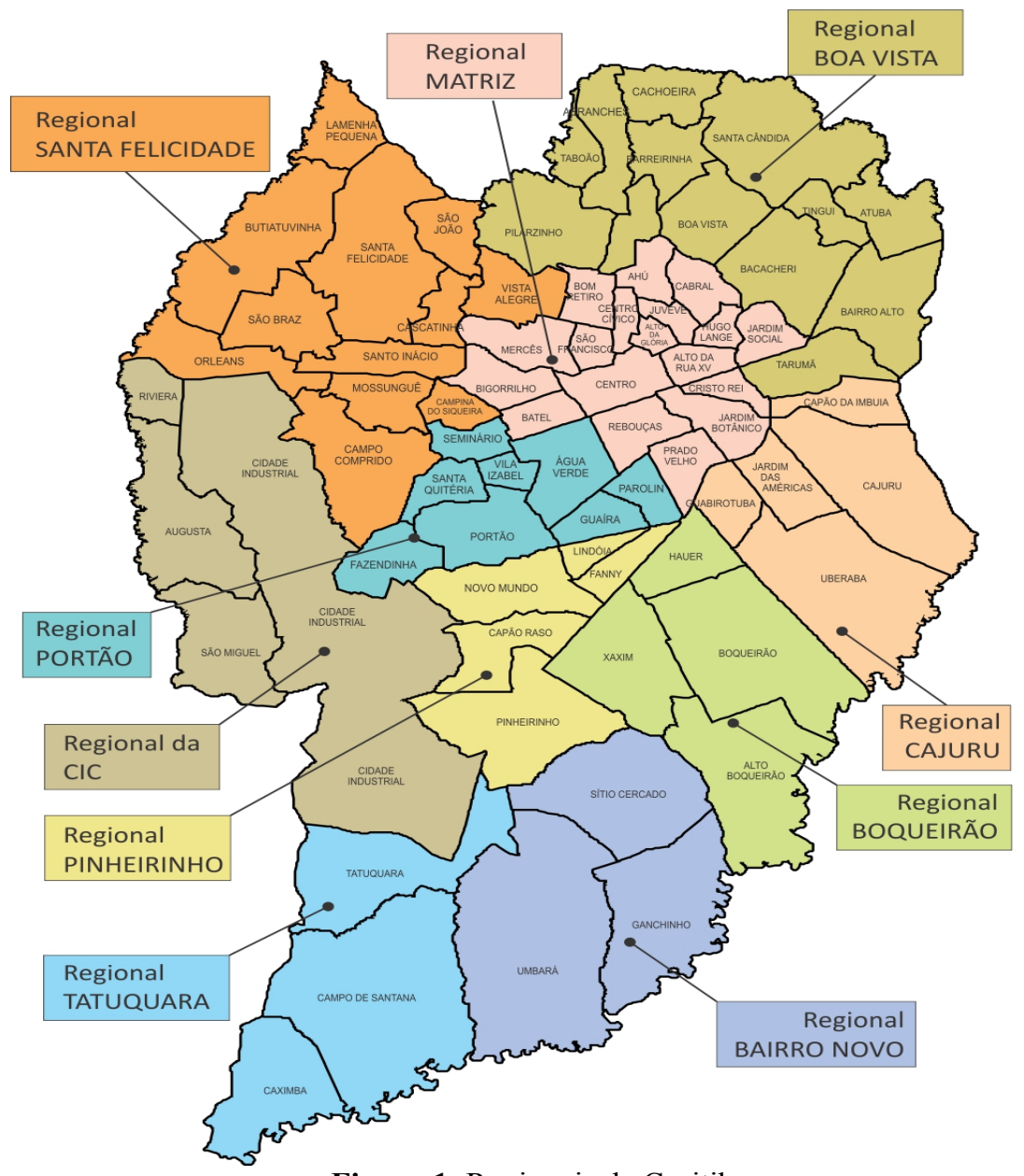

Figura 1: Regionais de Curitiba

Fonte: Prefeitura de Curitiba (2015).

Como se pode notar no mapa, os bairros periféricos aqui analisados estão localizados principalmente nas regionais Bairro Novo (em tom lilás) e Tatuquara (azul claro), ambas localizadas no sul do município, bem distantes dos bairros da região central (Matriz), onde se encontram as melhores condições de segurança, infraestrutura, mobilidade urbana e, como veremos a seguir, a maior quantidade de domicílios com acesso à internet.

\section{Educação a distância e a desigualdade no acesso à internet em bairros da região central e periférica de Curitiba}

As aulas presenciais na educação básica e no ensino superior foram suspensas por tempo indeterminado em vários países como medida para evitar a propagação do coronavírus. De acordo com o "Monitoramento global de fechamento de escolas causados pelo COVID19" realizado com base nos dados do Instituto de Estatística da UNESCO, na data de 16 de 
maio de 2020, constatou-se que 1.213.390.181 alunos foram afetados com o fechamento das escolas, representando $69,3 \%$ do total de alunos matriculados.

Curitiba, seguindo a tendência mundial, suspendeu o ensino presencial e a secretaria municipal de educação passou a oferecer material pedagógico especial, no formato de videoaulas. Através do decreto 516, publicado no Diário Oficial do Município do dia 8 de abril, em razão da pandemia de Covid-19, ficou estabelecido a suspensão das aulas em escolas, Centros Municipais de Educação Infantil (CMEIs), Centros Municipais de Atendimento Educacional Especializado (CMAEEs) e creches contratadas.

De acordo com o decreto, as aulas, dentro do currículo da rede, foram preparadas pela equipe técnica dos departamentos de Educação Infantil e Ensino Fundamental e o conteúdo, ministrado por professores da rede municipal de ensino, foi desenvolvido para o público da pré-escola, do $1^{\mathrm{o}}$ ao $5^{\mathrm{o}}$ ano do Ensino Fundamental e da Educação para Jovens e Adultos (EJA).

Para estudantes do $6^{\circ}$ ao $9^{\circ}$ ano do Fundamental, o conteúdo será o produzido pelo Governo do Estado. O conteúdo passou a ser apresentado no dia 13 de abril em videoaulas pela Paraná Turismo, canal 9.2 UHF e também através da internet pelo Youtube, como apresentado na figura 2.

Figura 2: Cartaz de divulgação da Educação a distância promovida pela Secretaria Municipal de Educação de Curitiba

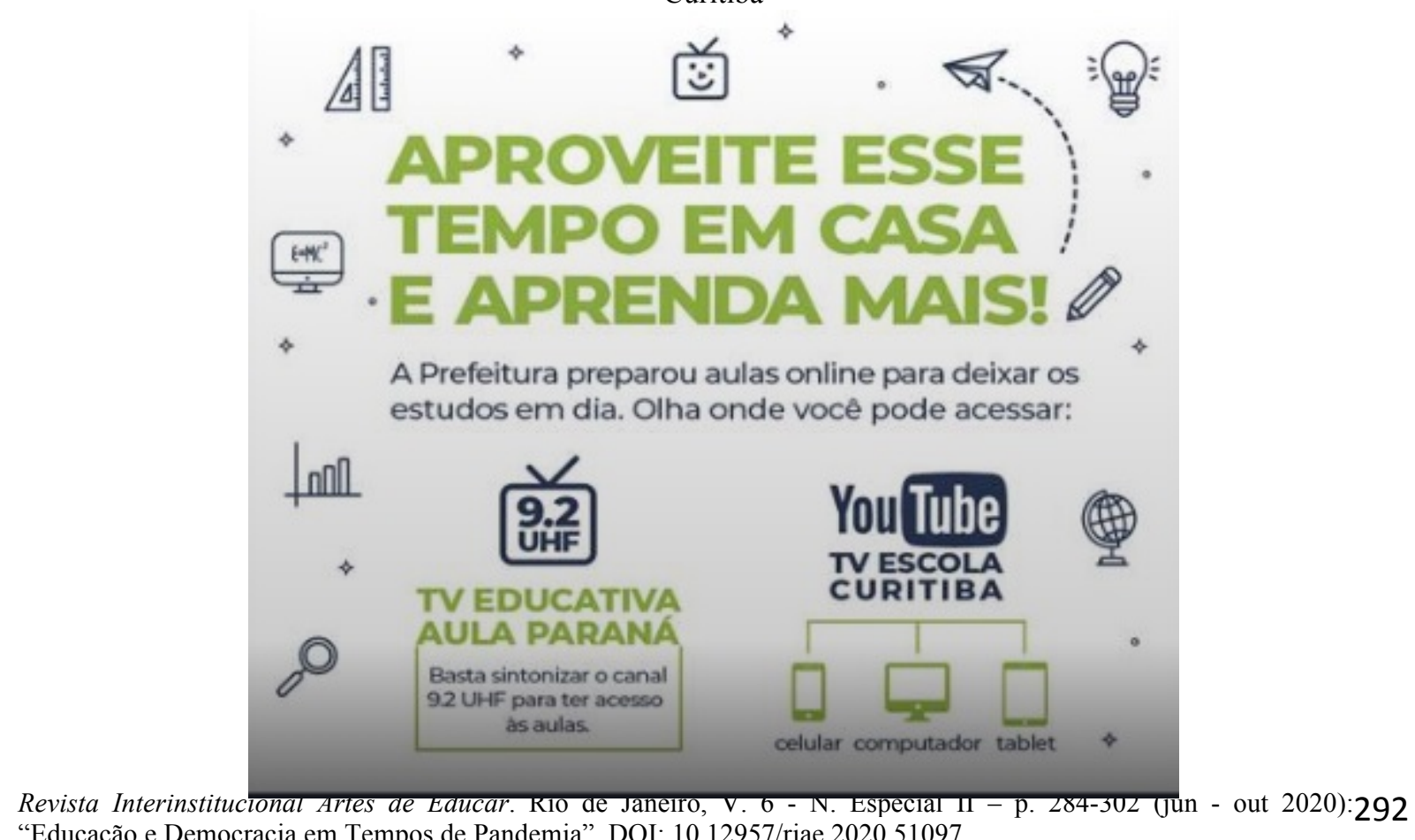


Em relação à educação infantil ficou determinado que os estudantes terão que registrar o acompanhamento das aulas, em cadernos ou folhas, os quais serão entregues posteriormente pelos pais ou responsáveis nas escolas. Para isso, a prefeitura distribui às famílias que precisarem, folhas, cadernos, lápis e demais materiais necessários para essas anotações.

Para os estudantes do Ensino Fundamental (do $6^{\circ}$ ao $9^{\circ}$ ano), a Secretaria Municipal de Educação firmou convênio com o governo estadual, que ficou responsável pela produção de conteúdo para este segmento, com aulas transmitidas em canais da televisão digital aberta com um canal exclusivo para os sextos e sétimos anos e outro para os oitavos e nonos. Também há o aplicativo Aula Paraná, onde o aluno pode acompanhar a aula ao vivo.

De acordo com a Secretaria Estadual de Educação, o aplicativo não consome dados de 3G e $4 \mathrm{G}$ e pode ser acessado, inclusive, em celulares pré-pagos. Além disso, a secretaria firmou parceria com o Google Classroom, que é um sistema de gerenciamento de conteúdo para escolas que permite a criação, distribuição e avaliação de trabalhos, permitindo também a interação entre o professor e o aluno. Ou seja, para este segmento da educação básica, o acesso à internet se faz ainda mais necessário.

O sistema de aulas a distância tem dividido opiniões perante a comunidade escolar pois, se por um lado viabilizou a oferta contínua das aulas e disponibilizou conteúdos e atividades para uma parcela de estudantes que tem acesso aos recursos tecnológicos; por outro, não contempla aqueles que vivem em condição de vulnerabilidade social em decorrência de fatores socioeconômicos e, consequentemente, não possuem acesso aos recursos tecnológicos necessários.

De fato, como demonstrado na figura 3, abaixo, a distribuição desigual da população no espaço urbano da cidade de Curitiba tem impactos sobre a acessibilidade à internet e, consequentemente, sobre os estudantes de segmentos sociais vulneráveis, residentes nos bairros da região periférica aqui analisados, uma vez que essa situação de brutal desigualdade no acesso, aprofunda ainda mais o fosso entre as diferentes classes sociais, com as mais vulneráveis desprovidas até mesmo de informações sobre a pandemia. 


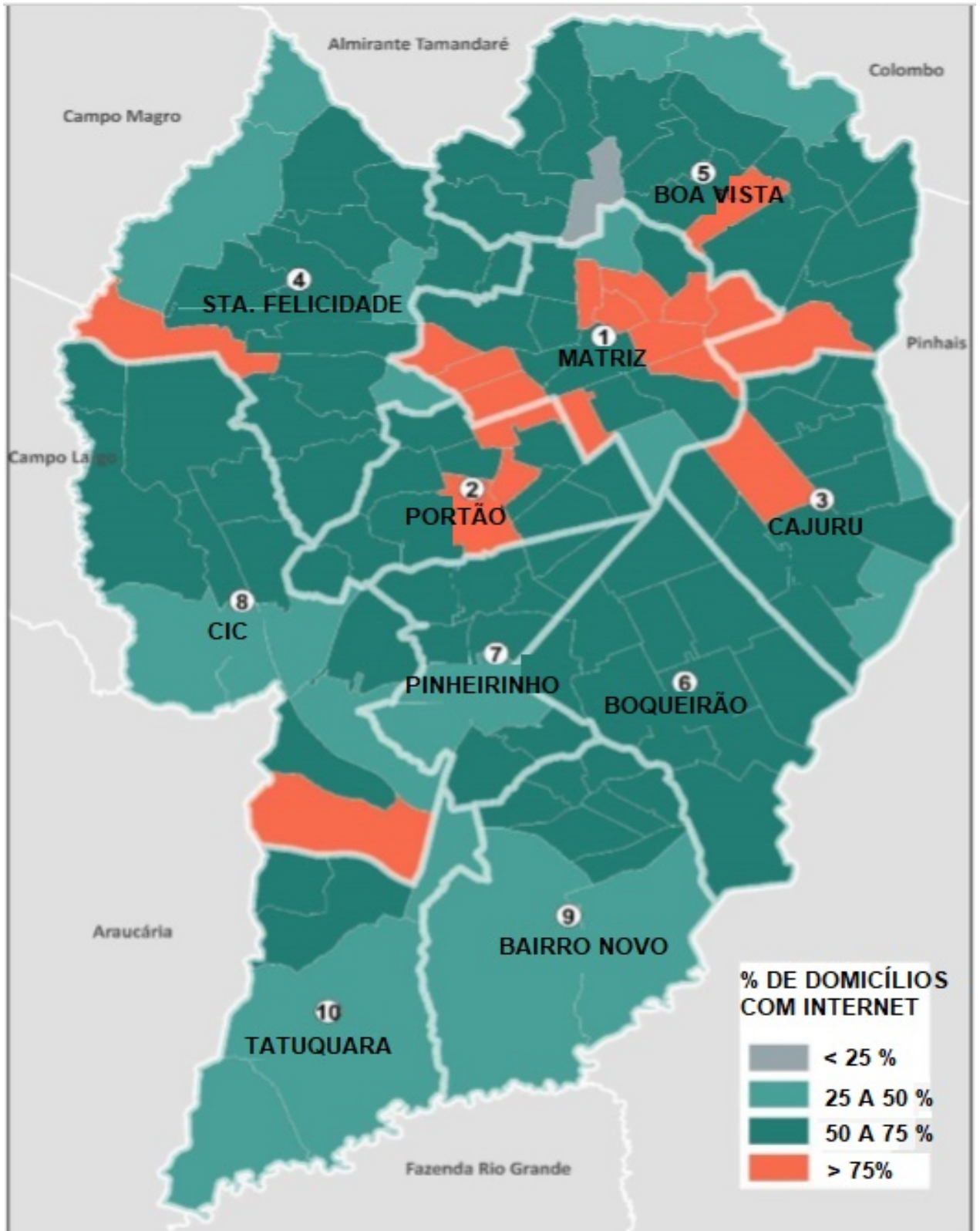

Figura 3: Porcentagem de domicílios com internet (por zona, município de Curitiba)

Fonte: IPPUC (2014).

A região, o bairro, o território é, também, capaz de gerar desigualdades. A análise do efeito-território que conduz a presente análise investiga as inter-relações entre as características tanto dos espaços (territórios) quanto dos grupos sociais presentes nestes.

De acordo com Andrade e Silveira (2013):

O efeito-território é compreendido na literatura sociológica como os benefícios ou prejuízos socioeconômicos que acometem alguns grupos sociais em função da sua localização no espaço social das cidades. A hipótese sociológica a respeito do efeito-território não pressupõe uma ação determinista do espaço sobre as relações sociais, mas investiga as interrelações entre as características dos espaços (tais como infraestrutura urbana, vizinhança, oferta de serviços) e as características dos grupos sociais (perfil 
do grupo e a natureza das suas interações internas e externas) (ANDRADE, SILVEIRA, 2013, p. 381).

De fato, os bairros periféricos analisados que apresentam a menor porcentagem de domicílios com internet são, também, os que apresentam o mais baixo Índice de Bem-Estar Urbano (IBEU) global e local, índice desenvolvido pelo Observatório das Metrópoles e que varia entre zero e um. Quanto mais próximo de um, melhor é o bem-estar urbano; quanto mais próximo de zero, pior é o bem-estar urbano.

O IBEU é composto por cinco dimensões: mobilidade urbana; condições ambientais urbanas; condições habitacionais urbanas; atendimento de serviços coletivos urbanos; e infraestrutura urbana.

Cada uma dessas dimensões, assim como o índice geral, é constituída por um conjunto de indicadores, obtidos na base de dados do Censo Demográfico do Instituto Brasileiro de Geografia e Estatística (IBGE) de 2010, extraídos tanto da base do universo (questionário básico) e da base de microdados (questionário amostral) quanto da base do entorno dos domicílios, agregados no nível das áreas de ponderação.

De acordo com Ribeiro e Ribeiro (2013):

trata-se de um índice que prioriza componentes de alcance coletivo e não individual, ou seja, aquilo que "a cidade deve proporcionar às pessoas em termos de condições materiais de vida (RIBEIRO; RIBEIRO, 2013, p. 9).

Ainda, de acordo com as autoras, o IBEU:

procura avaliar a dimensão urbana do bem-estar usufruído pelos cidadãos brasileiros promovido pelo mercado, via o consumo mercantil, e pelos serviços sociais prestados pelo Estado. Tal dimensão está relacionada com as condições coletivas de vida promovidas pelo ambiente construído da cidade, nas escalas da habitação e da sua vizinhança próxima, e pelos equipamentos e serviços urbanos (RIBEIRO; RIBEIRO, 2013, p. 7).

À título de comparação, a figura 4 apresenta o IBEU local aplicado à dimensão Infraestrutura Urbana.

Figura 4: IBEU local - Dimensão: Infraestrutura Urbana (2010) 

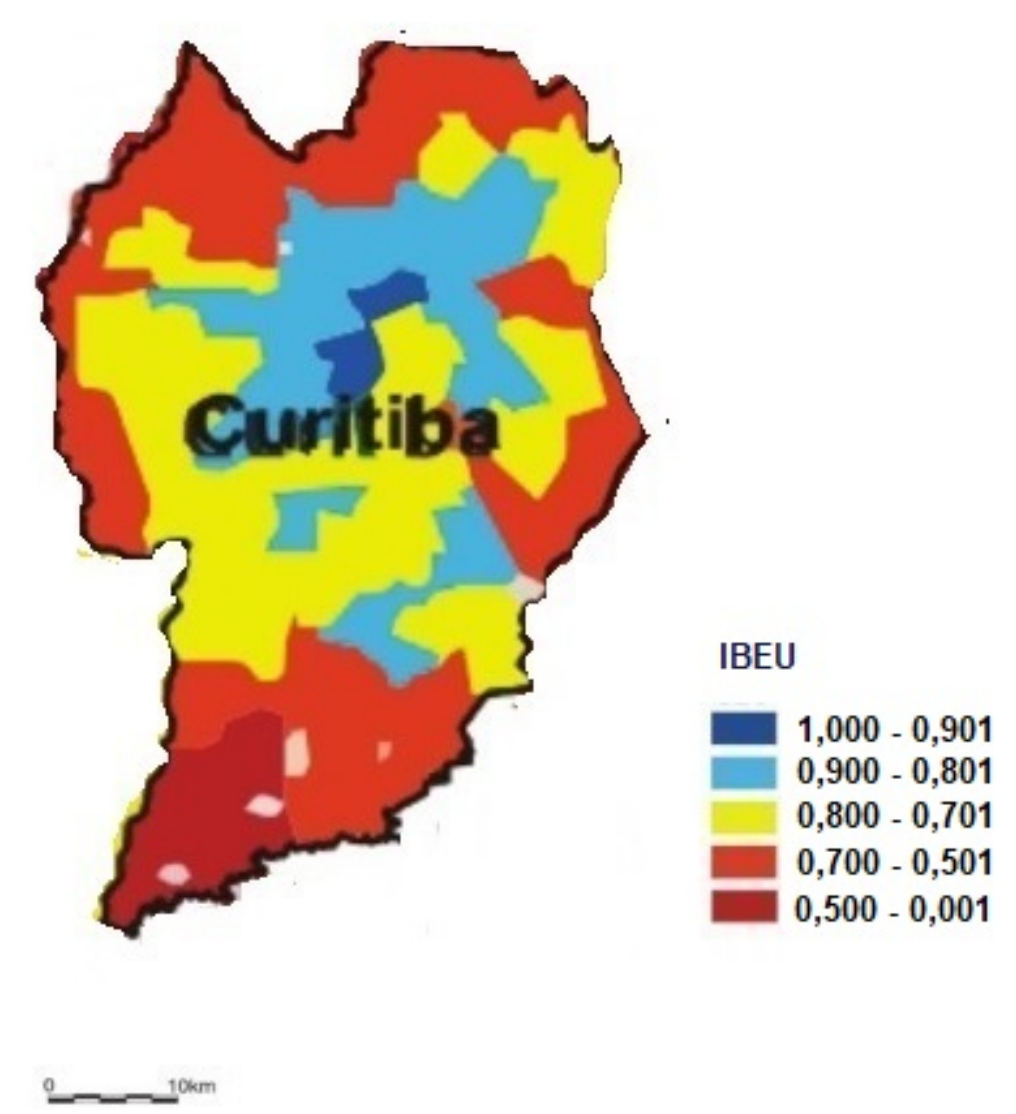

Fonte: Observatório das Metrópoles - Núcleo Curitiba (2013) e IPPUC (2014). Adaptado pelo autor.

A Infraestrutura Urbana abrange, entre outras dimensões, os espaços livres públicos, a infraestrutura viária e aquele que é considerado um dos mais graves problemas atuais: a segurança pública. Como demonstrado na figura 4, os bairros periféricos aqui analisados estão todos em patamares considerados ruins (com índices que variam de 0,501 a 0,700 ) ou muito ruins (com índices que variam de 0,001 a 0,500 ).

Ou seja, os bairros periféricos que apresentam os piores Índices de Bem-Estar Urbano são, também, os que apresentam as menores porcentagens de domicílios com acesso à internet, como reforçam os dados apresentados no gráfico 1 que mostram que as regionais da área central da cidade (Matriz e Portão) apresentam percentuais de 75\% e 72\%, respetivamente, sendo estas as únicas macro zonas com percentual superior à média do município.

No entanto, em relação aos bairros periféricos, verificou-se percentuais de $55 \%$ na regional Bairro Novo e 49\% na regional Tatuquara, as mais pobres do município.

Gráfico 1: Percentagem de domicílios com internet (por macro zona de Curitiba) 


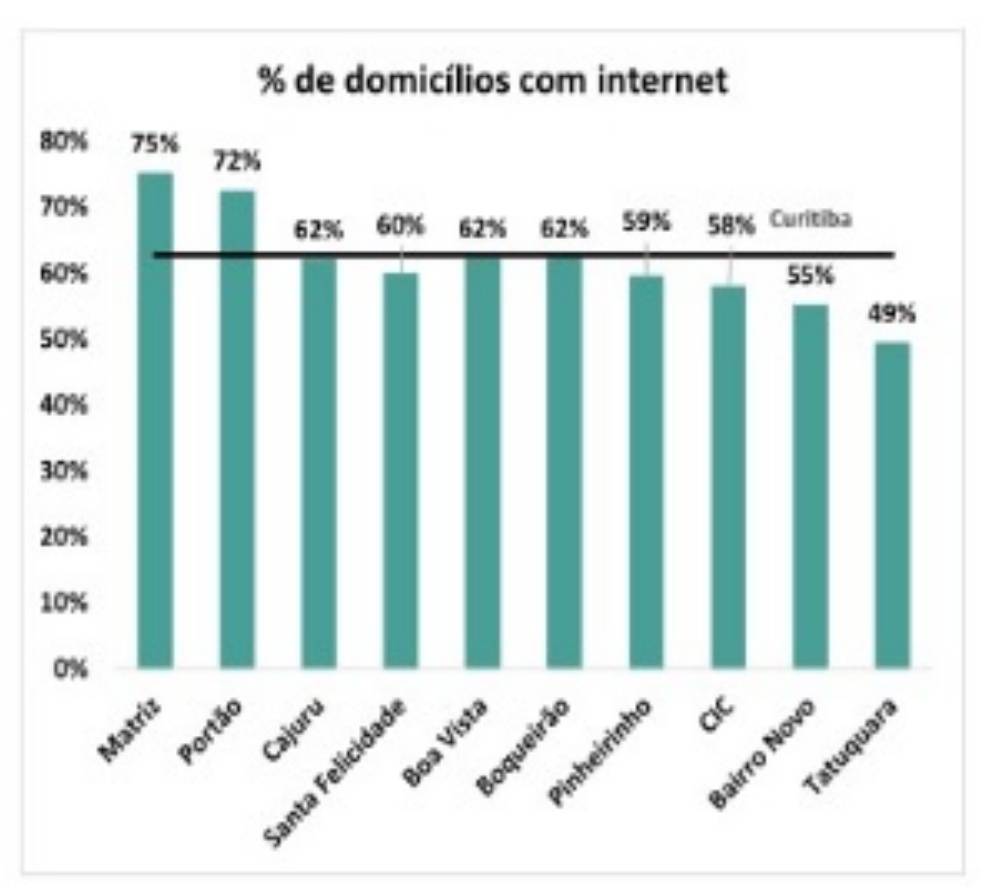

Fonte: IPPUC (2014).

A esse respeito é importante destacar que há, recentemente, uma convergência de estudos que tratam da segregação espacial como um fator impactante importante sobre as oportunidades educacionais. Tais estudos concentram seu foco em dois conceitos desenvolvidos no campo da sociologia urbana: o efeito vizinhança/bairro e a geografia de oportunidades.

Os estudos que partem do conceito de efeito vizinhança (Koslinski \& Alves, 2012) focalizam o impacto da concentração da pobreza sobre desfechos escolares individuais como abandono escolar, repetência, aprendizagem, etc.

De acordo com os referidos autores, tais estudos atingiram maior penetração no campo da sociologia da educação, principalmente no desenvolvimento de estudos quantitativos nos moldes dos estudos de efeito escola/eficácia escolar, utilizando novas técnicas estatísticas como os modelos hierárquicos.

Já o conceito de geografia de oportunidades, ainda pouco desenvolvido no campo dos estudos sobre desigualdades educacionais, está calcado na ideia de que a estrutura, a qualidade e o acesso a oportunidades, bem como a percepção sobre as oportunidades variam de acordo com as características socioeconômicas dos bairros/vizinhanças (Koslinski \& Alves, 2012).

Importante destacar, também, os estudos realizados no âmbito do grupo de pesquisa "Observatório da Educação e Cidades ${ }^{\mathrm{iv}}$ " que reúne trabalhos realizados no Brasil nas últimas 
décadas, com o objetivo de investigar e compreender o impacto da segregação residencial e/ou do efeito-vizinhança sobre oportunidades educacionais. Esses estudos partem do pressuposto de que a concentração da pobreza é um fator estrutural explicativo dos comportamentos individuais e, por extensão, dos resultados escolares.

Igualmente relevante são as pesquisas que tratam da relação entre segregação espacial e oportunidades educacionais utilizando-se de dados levantados pelo Instituto de Pesquisas Econômicas Aplicadas (IPEA), referência importante nos estudos sobre as mais variadas formas de desigualdade no Brasil. Utilizado desde 2010, o Índice de Vulnerabilidade Social (IVS), foi construído a partir de indicadores do Atlas do Desenvolvimento Humano (ADH) no Brasil $^{v}$ e procura dar destaque a diferentes situações indicativas de exclusão e vulnerabilidade social no território brasileiro, numa perspectiva que vai além da identificação da pobreza entendida apenas como insuficiência de recursos monetários (IPEA, 2015).

O Atlas da Vulnerabilidade Social nos Municípios Brasileiros (IPEA, 2015), já destacava a necessidade de um esforço para ampliar o entendimento das situações tradicionalmente definidas como de pobreza, buscando exprimir uma perspectiva ampliada complementar àquela atrelada à questão da insuficiência de renda. Assim como as noções de "necessidades básicas insatisfeitas", "pobreza multidimensional” e "desenvolvimento humano", exclusão e vulnerabilidade social. De acordo com o estudo, se trata de noções, antes de tudo políticas que introduzem novos recursos interpretativos sobre os processos de desenvolvimento social, para além de sua dimensão monetária. Nesse sentido, a leitura desses processos, resultante desta "nova" conceituação, pode dialogar e produzir efeitos sobre as propostas e os desenhos das políticas públicas, alargando seu escopo e colocando em evidência as responsabilidades do Estado, em todos os seus níveis administrativos, na promoção do bem-estar dos cidadãos (IPEA, 2015).

Bem-estar que, principalmente na atual conjuntura vivenciada, inclui a adoção de políticas públicas para garantir o acesso da população mais vulnerável à Internet. Segundo a pesquisa TIC Domicílios (2018), esta realidade ainda está longe de ser alcançada pois $85 \%$ dos usuários de Internet da classe D e E acessam a rede exclusivamente pelo celular, 2\% apenas pelo computador e $13 \%$ se conectam tanto pelo aparelho móvel quanto pelo computador. A pesquisa destaca, ainda, a necessidade de se buscar uma ótica ampliada da exclusão digital que ultrapasse a dimensão do acesso e leve em conta as disparidades referentes ao uso e à presença de habilidades digitais. De acordo com a publicação: 
Um olhar sobre as atividades on-line realizadas pelos usuários das camadas economicamente menos favorecidas, por exemplo, mostra um uso mais limitado e menos diversificado da Internet. É justamente entre esse público mais vulnerável que o acesso à rede realizado exclusivamente pelo telefone celular é mais intenso. Além disso, nesse segmento da população, é comum que a conexão do celular seja feita exclusivamente pelo WiFi, o que está relacionado também a uma frequência de uso mais baixa do que a encontrada nas demais classes sociais.

Certamente, essas restrições trazem implicações para esses indivíduos na mobilização de recursos (dispositivos e habilidades digitais) para que possam explorar as inúmeras oportunidades oferecidas pela rede e, consequentemente, consigam converter esse uso em benefícios tangíveis para as suas atividades pessoais e profissionais - o que indicaria a existência de um terceiro nível de exclusão digital (TIC DOMICÍLIOS, 2019, p. 2324).

Como procuramos demonstrar, ao analisar a desigualdade no acesso à internet em bairros da região central e periférica de Curitiba, o isolamento social de milhões de alunos preconizado como a principal forma de contenção da pandemia de Covid-19 - que tiveram as aulas presenciais suspensas, atendendo a recomendação da Organização Mundial de Saúde (OMS), tem revelado a enorme desigualdade no que tange a centralização das atividades na internet, incluindo a educação a distância (EAD), que - da forma como vem sendo adotada revela mais um aspecto da seletividade social das medidas adotadas pelo Estado no enfrentamento da doença.

\section{Considerações finais}

A análise do acesso à Internet com base em bairros da região central e periférica da cidade de Curitiba é, como procuramos demonstrar, mais um indicativo da seletividade social das medidas de isolamento recomendadas pelas autoridades sanitárias como forma de minimizar a propagação da Covid-19. Desde o dia 13 de abril, a Secretaria Municipal de Educação, amparada pelo decreto 516, estabeleceu a suspensão das aulas presenciais sob sua responsabilidade. Para os alunos da educação infantil, o conteúdo passou a ser apresentado em videoaulas pela Paraná Turismo e também através da internet pelo Youtube. Para os estudantes do Ensino Fundamental (do $6^{\circ}$ ao $9^{\circ}$ ano), a Secretaria Municipal de Educação firmou convênio com o governo estadual, que ficou responsável pela produção de conteúdo para este segmento, com aulas transmitidas em canais da televisão digital aberta com um canal exclusivo para os sextos e sétimos anos e outro para os oitavos e nonos, além do aplicativo Aula Paraná e da parceria com o Google Classroom. Ou seja, para este segmento da educação básica, o acesso à internet se faz ainda mais necessário. 
De acordo com os dados apresentados, constata-se que, em Curitiba, a EaD - ou ensino remoto emergencial - não tem se concretizado como uma alternativa capaz de atender de forma igualitária todos os estudantes, elevando ainda mais a desigualdade educacional entre os alunos. Os bairros periféricos que apresentam os piores Índices de Bem-Estar Urbano (IBEU) são, também, os que apresentam as menores porcentagens de domicílios com acesso à internet. Os dados apresentados revelam que as regionais da área central da cidade (Matriz e Portão) apresentam percentuais de $75 \%$ e $72 \%$, respetivamente. No entanto, em relação aos bairros periféricos, verificou-se percentuais de 55\% na regional Bairro Novo e $49 \%$ na regional Tatuquara, as mais pobres do município.

Os dados se coadunam com os demais estudos que tratam da segregação espacial como um fator impactante importante sobre as oportunidades educacionais revelando que há um efeito-território - compreendido na literatura sociológica como os benefícios ou prejuízos socioeconômicos que acometem alguns grupos sociais em função da sua localização no espaço social das cidades - que também se manifesta através da desigualdade no acesso à Internet. Outro aspecto a ser considerado é o fato de $85 \%$ dos usuários de Internet das classes D e E acessarem a rede exclusivamente pelo celular, como divulgado pela pesquisa TIC Domicílios (2018), revelando a necessidade de se buscar uma ótica ampliada da exclusão digital que ultrapasse a dimensão do acesso e leve em conta, também, as disparidades referentes ao uso e à presença de habilidades digitais.

Portanto, o mapeamento das diferentes situações indicativas de exclusão e vulnerabilidade social na cidade de Curitiba pode contribuir para a elaboração de políticas públicas que visem, de fato, a redução de desigualdades sociais consideradas como catalisadoras da Covid-19. A educação a distância - por não contemplar parcela significativa daqueles que vivem em condição de vulnerabilidade social e que não possuem acesso aos recursos tecnológicos necessários - tem revelado outro aspecto da seletividade social das medidas adotadas pelo município no enfrentamento da pandemia. Nesse sentido, diante de um futuro incerto, a democratização do acesso à internet se faz urgente, uma vez que, em razão do isolamento social, não apenas os serviços educacionais, mas o conjunto mais amplo de serviços públicos prestados aos cidadãos se dará, cada vez mais, através da Internet.

\section{Referências}

ALBUQUERQUE, A1. A questão habitacional em Curitiba: o enigma da “cidade modelo". Dissertação de mestrado. FAU-USP, São Paulo, 2007. 
ANDRADE, L. T.; SILVEIRA, L. S. Efeito-território: explorações em torno de um conceito sociológico. Civitas, Porto Alegre, v. 13, n. 2, p. 381-402, 2013.

ARANTES, P. F. Em busca do urbano: Marxistas e a cidade de São Paulo nos anos de 1970. Revista Novos Estudos. Cebrap. 2009.

CARVALHO, A. S.; SUGAI, M. I. A produção da cidade segregada: o caso de Curitiba. In: II Simpósio de Estudos Urbanos: A dinâmica das cidades e a produção do espaço, 2013, Campo Mourão. II Simpósio de Estudos Urbanos: A dinâmica das cidades e a produção do espaço. Campo Mourão: FECILCAM, 2013.

CURITIBA. Diário Oficial Eletrônico. Atos do Município de Curitiba. Decreto $n^{\circ} 516$, de 8 de abril de 2020, Decreta a suspensão das aulas em escolas, Centros Municipais de Educação Infantil (CMEIs), Centros Municipais de Atendimento Educacional Especializado (CMAEEs) e creches contratadas. 2020.

IPPUC. Consolidação de dados de oferta, demanda, sistema viário e zoneamento. Relatório 5. Pesquisa Origem-destino domiciliar. 2017.

KOSLINSKI, M. C.; ALVES, F. Novos olhares para as desigualdades de oportunidades educacionais: a segregação residencial e a relação favela-asfalto no contexto carioca. Educ.Soc., Campinas, v. 33, n. 120, p. 805-831, jul.-set. 2012.

LOJKINE, J. O Estado capitalista e a questão urbana. São Paulo: Martins Fontes, 1997.

NERI, M. (coord.). Mapa da Inclusão Digital. Rio de Janeiro: FGV, CPS, 2018.

PRETTO, N. De L.; BONILLA, M. H. S.; SENA; I. P. F. de S. (Orgs). Educação em tempos de pandemia: reflexões sobre as implicações do isolamento físico imposto pela COVID-19. Salvador: Edição do autor, 2020.

RIBEIRO; L.C. de Q.; RIBEIRO, M.G. (Org.). IBEU: indice de bem-estar urbano. 1ª. Ed. Rio de Janeiro: Letra Capital, 2013, 264 p. Disponível em: http://www.observatoriodasmetropoles.net/images/abook_file/ibeu_livro.pdf. Acesso em: out. 2019.

TIC DOMICÍLIOS 2018. Comitê Gestor da Internet no Brasil - CGI.br. Pesquisa Sobre o Uso das Tecnologias de Informação e Comunicação nos Domicílios Brasileiros - São Paulo: CGI.br, 2019. Disponível em: https://www.cetic.br/pesquisa/domicilios/ . Acesso em: 15 maio 2020. 
Doutor em Sociologia. Mestre em Políticas Educacionais. Bacharel em Ciências Sociais. Pesquisador do grupo de pesquisa "Políticas sociais: análise comparada das experiências brasileiras", do "Programa de Desenvolvimento Urbano e Regional - PDUR" e do Observatório das Metrópoles - Núcleo Curitiba. Pesquisador do Programa de Pós-graduação em Sociologia na UFPR, onde realiza estágio pós-doutoral pelo PNPD/Capes. E-mail: 666noma@gmail.com. Orcid iD: https://orcid.org/0000-0002-6780-8974

ii Mestranda em Sociologia pela Universidade Federal do Paraná (PROFSOCIO). Bacharel e Licenciada em Ciências Sociais com Pós Graduação em Coordenação Pedagógica e Educação Especial Inclusiva com Ênfase na Deficiência Intelectual. Professora de sociologia vinculada a Secretaria de Estado da Educação do Paraná. E-mail: lislaineguimaraes@yahoo.com.br. Orcid iD: https://orcid.org/0000-0002-5823-0090

iii O IDHM brasileiro considera as mesmas três dimensões do IDH Global - longevidade, educação e renda, mas vai além: adequa a metodologia global ao contexto brasileiro e à disponibilidade de indicadores nacionais. Embora meçam os mesmos fenômenos, os indicadores levados em conta no IDHM são mais adequados para avaliar o desenvolvimento dos municípios e regiões metropolitanas brasileiras.

iv O Observatório da Educação e Cidades se consolidou como um núcleo de pesquisa que tem como temática central as desigualdades de oportunidades educacionais no Brasil, considerando de forma integrada os diferentes contextos e agentes atuantes nesse processo: o da cidade, o da escola e o da família. O desenvolvimento do Observatório teve início com a colaboração do Observatório das Metrópoles do Instituto de Pesquisa e Planejamento Urbano e Regional (IPPUR/UFRJ) e do Laboratório de Avaliação da Educação (LAEd/Departamento de Educação da PUC-Rio) em março 2006. Mais recentemente, foram incorporados ao Observatório pesquisadores do Grupo de Estudos e Pesquisas dos Sistemas Educacionais (GESED) da Faculdade de Educação (UFRJ).

v Atlas do desenvolvimento humano no Brasil (ADH) é uma plataforma de consulta ao Índice de Desenvolvimento Humano Municipal (IDHM), de 5.565 municípios brasileiros, aplicados às 27 Unidades da Federação (UFs), vinte regiões metropolitanas (RMs) e suas respectivas Unidades de Desenvolvimento Humano (UDH). O ADH engloba o Atlas do desenvolvimento humano nos municípios e o Atlas do desenvolvimento humano nas RMs e traz, além do IDHM, mais de duzentos indicadores de demografia, educação, renda, trabalho, habitação e vulnerabilidade. 